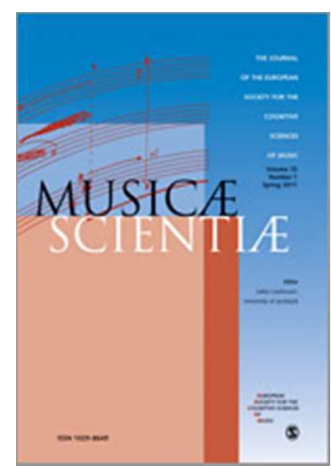

\title{
Group Behaviour and Interpersonal Synchronization to Electronic Dance Music
}

\begin{tabular}{|c|c|}
\hline Journal: & Musicae Scientiae \\
\hline Manuscript ID & MS-16-0053.R2 \\
\hline Manuscript Type: & Original Manuscript \\
\hline Keywords: & $\begin{array}{l}\text { dance, group behaviour, interpersonal synchronization, motion capture, } \\
\text { embodiment, electronic dance music }\end{array}$ \\
\hline Abstract: & $\begin{array}{l}\text { The present study investigates how people move and relate to each other } \\
- \text { and to the dance music - in a club-like setting created within a motion } \\
\text { capture laboratory. Three groups of participants ( } 29 \text { in total) each danced } \\
\text { to a 10-minute-long DJ mix consisting of four tracks of electronic dance } \\
\text { music (EDM). Two of the EDM tracks had little structural development, } \\
\text { while the two others included a typical 'break routine' in the middle of the } \\
\text { track, consisting of three distinct passages: (a) 'breakdown,' (b) 'build-up' } \\
\text { and (c) 'drop'. The motion capture data shows similar bodily responses for } \\
\text { all three groups in the break routines: a sudden decrease and increase in } \\
\text { the general quantity of motion. More specifically, the participants } \\
\text { demonstrated an improved level of interpersonal synchronization after the } \\
\text { drop, particularly in their vertical movements. Furthermore, the } \\
\text { participants' activity increased and became more pronounced after the } \\
\text { drop. This may suggest that the temporal removal and reintroduction of a } \\
\text { clear rhythmic framework, as well as the use of intensifying sound } \\
\text { features, have a profound effect on a group's beat synchronization. Our } \\
\text { results further suggest that the musical passages of EDM efficiently lead to } \\
\text { the entrainment of a whole group, and that a break routine effectively 're- } \\
\text { energizes' the dancing. }\end{array}$ \\
\hline
\end{tabular}

\section{SCHOLARONE ${ }^{\text {M }}$ \\ Manuscripts}


Running head: GROUP SYNCHRONIZATION TO EDM

\begin{abstract}
The present study investigates how people move and relate to each other - and to the dance music - in a club-like setting created within a motion capture laboratory. Three groups of participants (29 in total) each danced to a 10-minute-long DJ mix consisting of four tracks of electronic dance music (EDM). Two of the EDM tracks had little structural development, while the two others included a typical 'break routine' in the middle of the track, consisting of three distinct passages: (a) 'breakdown,' (b) 'build-up' and (c) 'drop'. The motion capture data shows similar bodily responses for all three groups in the break routines: a sudden decrease and increase in the general quantity of motion. More specifically, the participants demonstrated an improved level of interpersonal synchronization after the drop, particularly in their vertical movements. Furthermore, the participants' activity increased and became more pronounced after the drop. This may suggest that the temporal removal and reintroduction of a clear rhythmic framework, as well as the use of intensifying sound features, have a profound effect on a group's beat synchronization. Our results further suggest that the musical passages of EDM efficiently lead to the entrainment of a whole group, and that a break routine effectively 're-energizes' the dancing.
\end{abstract}

Keywords: dance; group behaviour; interpersonal synchronization; motion capture; embodiment, electronic dance music. 


\section{Group Behaviour and Interpersonal Synchronization to Electronic Dance Music}

\section{Introduction}

Music has the ability to make people move, for example through head nodding, hip swaying, foot tapping, or regular dancing (Godøy \& Leman, 2010). Such spontaneous music-induced activity may attest to how integrated movements are in many music-related activities, and particularly that of dance. The fact that music and dance are so closely connected, and even inseparable in some cultures, has led to the suggestion that the two have co-evolved over time (Cross, 2001, 2008). Both music and dance, and the combination of the two, are also highly social and collective in nature (Brown, Merker, \& Wallin, 2000). Our research interest lies in exploring this social nature of music and dance, through empirical studies of people's behaviour to electronic dance music (EDM). We have previously studied pleasure and intersubjectivity in a motion capture experiment of EDM dancing (Solberg \& Jensenius, 2016b). In the present article we focus on sensorimotor and interpersonal synchronization, with empirical results from a new group dance experiment.

\section{Sensorimotor Synchronization}

Sensorimotor synchronization can be defined as "the temporal coordination of a motor rhythm with an external rhythm" (Repp, 2005, p. 969). The human predisposition to synchronize our bodies to musical features can be seen at an early stage of development, as even infants are able to synchronize to music and display happiness when moving (Zentner \& Eerola, 2010) and children display periodicity in their movements to music (Eerola, Luck, \& Toiviainen, 2006). A growing body of music psychological research has focused on how, why, and in what way, we synchronize our bodies to music (see, for instance, Janata, Tomic, \& Haberman, 2012; Repp, 2005; Repp \& Su, 2013), more recently also from more embodied approaches (Leman, 2008; Leman \& Naveda, 2010).

Rhythm is an important element of music, and particularly in dance music. There are indications of a relationship between perceived groove and motor activity in the brain (Stupacher, Hove, Novembre, Schültz-Bosbach, \& Keller, 2013) in addition to activation in the motor area of the brain when listening to rhythms with strong beat (Chen, Penhune, \& 
Zatorre, 2008; Grahn \& Brett, 2007). This link between body movement and musical beat is also shown in the study of Phillips-Silver and Trainor (2007), who found that head movement is particularly important for how rhythm and meter are perceived. Additionally, it has been found that we move more easily to music with a clear beat and a strong rhythmic focus (Burger, 2013), that vertical movement embody the beat level (Toiviainen, Luck, \& Thompson, 2010), and that people's movements are influenced by pulse clarity and spectral flux in low and high frequency components (Burger, Thompson, Luck, Saarikallio, \& Toiviainen, 2013). In particular, high pulse clarity in the music seems to lead to more, faster and more periodic movement (Burger, Thompson, Luck, Saarikallio, \& Toiviainen, 2014). Furthermore, "happy" and energized music seems to lead to more complex movement patterns, while slower music and music with a lower energy level is often associated with smaller movements (Burger, Saarikallio, Luck, Thompson, \& Toiviainen, 2013; Burger, Thompson, Saarikallio, Luck, \& Toiviainen, 2010). The bass drum is of particular importance for the level of movement and entrainment (Van Dyck et al., 2013), and our arms synchronize with faster and higher metrical levels, while body swaying and rotation are linked to lower metrical levels of the music (Toiviainen et al., 2010).

\section{Interpersonal Synchronization}

The ability to synchronize bodily to external rhythmic patterns can be found at many different levels: intra-individual, intra-group and inter-group (Clayton, Dueck, \& Leante, 2013). Such synchronization does not only happen in music and dance, but also in a variety of other human activities such as sports, military drill, and verbal communication (McNeill, 1995; Phillips-Silver, Aktipis, \& Bryant, 2010). Most studies on sensorimotor synchronization have focused on one subject at a time, with some notable exceptions (Drake, Penel, \& Bigand, 2000; Ellamil, Berson, Wong, Buckley, \& Margulies, 2016; Snyder \& Krumhansl, 2001; Tarr, Launay, \& Dunbar, 2016; Van Dyck et al., 2013). The social aspect of moving to music, an arguably important element when trying to understand musical experiences, has to a lesser degree been taken into consideration when designing research experiments. Furthermore, among the comparably few studies that have focused on how we 
entrain to others (and to music), most have focused on other activities than dancing, such as, tapping, walking, speaking and treadmill running (for an overview, see Repp \& Su, 2013).

Even though few studies have been carried out on the effects of group dancing, there are some important findings in the literature. It has been found that people are able to synchronize their movements to each other and that music enables a group of people to move in a more effective and energetic manner (McNeill, 1995). It is also interesting that people move more when moving together (De Bruyn, Leman, \& Moelants, 2008) and that they also synchronize better when they see each other (Desmet, Leman, Lesaffre, \& de Bruyn, 2010). Furthermore, moving together has a positive impact on people's social and affective state (Marsh, Richardson, \& Schmidt, 2009; Merker, Madison, \& Eckerdal, 2009; Wiltermuth \& Heath, 2009). Moving together improves affiliation (Hove \& Risen, 2009), and it also contributes to our ability to help and collaborate with others (Kirschner \& Tomasello, 2009; Wiltermuth \& Heath, 2009). A shared (musical) experience creates social bonds, which in turn is related to the pleasure of moving our bodies together with others (Pressing, 2002).

In sum, dancing with others leads to various changes in our human behaviour, displays an increased ability in cooperative behaviour, social bonding and closeness in addition to group cohesion (Freeman, 2000). Our pain threshold is elevated during interpersonal synchronization (Tarr et al., 2016), and participants even breathe together both when performing synchronized movements and when resting (Codrons, Bernardi, Vandoni, \& Bernardi, 2014). In a silent disco study where two groups danced to different music, people had better memory of those who danced to the same music than of the other group. This shows that rhythmic entrainment also affects our memory in social situations (Woolhouse, Tidhar, \& Cross, 2016). Synchronization also increases our self-reported feelings of social closeness (Tarr et al., 2016) when synchronized both with others and the music.

An action-perception loop seems to be activated when people synchronize to music, which leads to blurred lines in our perception of ourselves and others (Overy \& Molnar-Szakacs, 2009). This may again lead to social bonding between the participants involved, which can explain why such behaviour increase affiliation (Hove \& Risen, 2009). However, most studies on social bonding is related to small body movements carried out in 
small groups (Demos, Chaffin, Begosh, Daniels, \& Marsh, 2012; Reddish, Bulbulia, \& Fischer, 2014; Wiltermuth \& Heath, 2009), and few studies have investigated group effect in dancing. To our knowledge, lab studies on group behaviour have mainly focused on groups of a size up to five participants (Tarr et al., 2016; Van Dyck et al., 2013).

Most studies on interpersonal synchronization occur in artificial laboratory settings, and there have been few studies of group dancing in club environments. Van Dyck et al. (2013) have done pioneering work in creating a club-like atmosphere in a motion capture lab, and this is the former study that most resembles our own. However, they had a different focus: the importance of the sound level of the bass drum in dancing to EDM. Another related study is that of Ellamil et al. (2016), which is based on motion tracking in a real-life club setting. Using the accelerometer data from mobile phones, they found that the movement of the torso (front-back) were most associated with pulsations that approximate walking rhythm (100-150 bpm).

\section{The Club Setting and Features of Electronic Dance Music}

The nightclub constitutes the natural setting for dancing to EDM. The main focus is to dance together with others to a loud and continuous stream of music, with light effects surrounding the dancing crowd in an otherwise darkened space. Sonically, EDM can be described as a repetitive and rhythmically based music style, it is produced electronically and the musical elements are most often introduced, changed or removed after two, four, eight or sixteen bars. It contains a strong beat in 4/4 and the tempo usually lies between 120-130 beats per minute (BPM) (Butler, 2006).

EDM tracks include some specific structural conventions, one of the more important being what we refer to as the break routine. A break routine is a musical passage that consists of three elements: (a) breakdown, (b) build-up, and (c) drop, as seen in Figure 1. The break routine and each of its three constituent elements are produced so as to deviate from the regular flow of the track, based on large and sudden structural, textural and dynamical changes (Solberg \& Jensenius, 2016b). Thus during the break routine the track is first reduced to only a few of the musical features of the main groove. Often the rhythmic 
framework-especially the bass and the bass drum—is removed in the breakdown before the elements are reintroduced one at a time during the build-up. Also, intensifying sound effects are added during this passage. The musical peak comes when the bass or drumbeat is 'dropped' back into the groove. As such, the musical intention of the break routine is to create intensity peaks in the dance and music experience. We are particularly interested in seeing if such intensity peaks can also be observed in the behaviour of the dancers.

[Insert Figure 1]

\section{Research Aims, Questions and Hypotheses}

The present study focused on investigating how musical and social factors influence interpersonal musical experiences. We were interested in understanding more about how the dancers in separate groups engaged with each other during a dance session, and how both individuals and the groups as a whole related to the musical features. The research questions can be summarized as:

$\left(R Q_{1}\right)$ How does each of the groups move in relation to the music? Are there any similarities or differences in how the groups respond to the tracks?

$\left(R Q_{2}\right)$ How does the break routine influence the behaviour of the participants in the group?

$\left(R Q_{3}\right)$ Does the level of (interpersonal) synchronization change during the dance session, and when and how does this change happen?

From these questions we set up four hypotheses based on findings in the literature:

$\left(H_{1}\right)$ EDM tracks encourage synchronization to the beat. This is based on findings of the importance of pulse clarity on music-induced movement (Burger, Thompson, Luck, Saarikallio, \& Toiviainen, 2012).

$\left(H_{2}\right)$ The removal and reintroduction of the bass drum will influence people's synchronization under and after the break routine. This is according to the findings of the importance of the bass drum by Van Dyck et al. (2013), but also the importance of large and sudden changes in dynamics, texture and structure in the musical sound (Solberg \& Jensenius, 2016b). 
$\left(H_{3}\right)$ Dancing together with others will make the participants and groups move more similarly to the music, since synchronization increases social closeness (Tarr et al., 2016). We expect this to be especially apparent in how the structural properties of the tracks will guide the quantity and quality of the participants' dancing, since energized music leads to movement patterns of a more complex nature than music with lower energy levels (Burger, Saarikallio, et al., 2013; Burger et al., 2010).

$\left(H_{4}\right)$ The participants will show an increased level of interpersonal synchronization right after the drop, where the beat is stronger and more obvious. We predict this improved interpersonal synchronization to be visible in a more obvious vertical pattern, since vertical movement is known to embody the beat level (Toiviainen et al., 2010).

In addition to the empirical results, we also see the present study as a continuation of our focus on developing better methods for (more) ecologically valid research designs both inside and outside of a motion capture lab.

\section{Method}

\section{Participants}

Twenty-nine participants (15 female, 14 male) aged 19-52 years old ( $M=22.3$ years, $S D=6.58$ ) took part in the study. All participants were recruited during the semester start-up activities for musicology students at the University of Oslo. Being music students, they all had musical training and they engaged in music-related activities (listening, performing, creating) for 2.90 hours per day on average. The majority of the participants reported that they occasionally dance to music at home (31\% danced $1-3$ times a month, while 34\% 1-3 times a week) and at clubs (31\%: 1-3 time a month, and 21\% 1-3 times a week). During the dance session, the majority of the participants reported that they experienced a desire of their own to dance $(76 \%=$ 'All the time'-'Often' $)$.

The experiment was carried out in the evening, and the participants were treated with pizza and non-alcoholic refreshments prior to and after the dancing. As such, they had already started socialising before taking part in the study, hence the context felt natural and 
relaxed. The participants were randomly distributed into three groups, with each group consisting of 9-10 people.

All participants answered a brief questionnaire just after the dancing session was completed with questions about demographics, music/dance habits in addition to their experience of the music. Ethical approval was granted from the Norwegian Centre for Research Data, and all participants signed an informed consent form prior to the experiment. They were also informed that they were free to withdraw from the experiment at any point in time.

\section{Music Examples}

The music used in the experiment consisted of two fixed DJ mixes with the same four recently-produced EDM tracks used in our previous study (Solberg \& Jensenius, 2016b). The mixes included the same tracks, but organized differently to avoid order effects, as seen in Tables 1 and 2. Both mixes lasted for 10 minutes, and Groups A and C danced to DJ mix 1 while Group B danced to DJ mix 2. The four tracks were excerpts from real dance music and they were beat-matched and mixed to provide the participants with a continuous, club-like sound experience. The music was played back loudly through an immersive 47-channel sound system in the motion capture lab. The sound level of the music was estimated to be around 95 $\mathrm{dB}$, which both secures the ecological validity perspective as well as the Norwegian health and safety regulations.

\section{[Insert Tables 1 and 2]}

\section{Motion Capture Recordings}

The dance sessions were carried out in the motion capture lab at the Department of Musicology. Fortunately, the lab is located next to the canteen area within which the students had gathered for their social semester start event. We turned the lab into a club-like setting by switching off the main lights, hanging a disco ball from the ceiling and installing a rotating and colour-changing lighting system. The recording was made using a state-of-the-art infrared, marker-based motion capture system from Qualisys with 13 cameras (nine Oqus 300 and four Oqus 400) where each of the participants were equipped with one reflective head marker. 
In our previous study we had equipped all participants with markers on the head and wrists to be able to capture both overall body movement as well as arm movement (Solberg \& Jensenius, 2016b). It turned out, however, that the wrist markers were occluded most of the time, since the participants danced so closely together that the cameras could not see the markers. Furthermore, we also experienced problems with reliably tracking individual head markers, since many of the participants would lift their hands above their heads, which confused the motion tracking algorithm. So while the overall fill level of the recording was satisfactory, it was not possible to track individual markers throughout the session.

For the current study we therefore took several measures to improve the quality of the tracking (Solberg \& Jensenius, 2016a). First, we added more motion capture cameras to the setup, with four Oqus 400 cameras pointing downwards from the ceiling in addition to the nine Oqus 300 cameras positioned around the capture space. Second, we increased the frame rate to $200 \mathrm{~Hz}$ to account for the speed and complexity of the movement (Song \& Godøy, 2016). Third, the Qualisys system was calibrated at head height $-1.60 \mathrm{~m}$ above the floor-to further reduce possible measurement errors. Fourth, we decided to use only head markers due to our previous problems with tracking wrist markers.

As a backup measure, in case there would be problems with the infrared tracking, all participants were equipped with inertial sensors around the wrists (AX3 sensors from Axivity). So a total of 10 reflective markers and 20 accelerometers were used for each recording, in addition to reference video recordings made with the 'night-mode' on a Canon prosumer camera. In the present article we will only analyse the data sets from the Qualisys system, since they turned out to have a fill level close to $100 \%$ for almost all participants. There were a few missing frames in Group A, but these were estimated to have no impact on the average values used for the analyses, and the data from these participants was therefore also included in the data set.

\section{Procedure}

Ecological validity was a high priority in both the set-up and execution of the experiment. We therefore decided to leave the lab door open prior to the experiments, with 
loud music being played and with the light effects in action. That way the participants were able to familiarize themselves with the setting and set-up as they moved into the canteen area for their social gathering. The participants entered the lab in groups of 9-10 people. They were there equipped with the two wristbands and one reflective head marker. The only instruction given was that they should move to the 10 minutes of EDM similar to what they would do in an actual club setting. In other words, the groups were free to move around as much —or as little — as they wanted, but we encouraged them to keep within the marked area $(5 \times 3.50 \mathrm{~m})$ in the centre of the room. Immediately after the dance session the participants were asked to answer a short questionnaire.

After the dance sessions, the motion capture data sets were post-processed and exported from the Qualisys Track Manager (QTM). Almost all the motion trajectories had close to $100 \%$ fill level, so there was no need to fill in empty frames (gap-filling) or smooth the data prior to exporting from QTM. The files were imported in MATLAB using the MoCap Toolbox (Burger \& Toiviainen, 2013). The analysis has been done in Matlab and SPSS.

\section{Results}

We examined the groups' horizontal and vertical movement patterns, as well as their over-all movement tendencies. The analysis was particularly focused on the break routines.

\section{Horizontal Movement}

First the horizontal movement pattern was investigated. The groups' general movement tendencies to the entire DJ mixes can be seen in Figure 2, which presents a bird's eye perspective on the participants' distribution in the horizontal plane (XY). The plots indicate how the participants positioned themselves in relation to the others, and how (much) they moved around on the dance floor:

- Group A made the most use of the floor, the participants moved a lot and shifted positions during the session. 
- Group B moved most homogeneously, with all of the participants dancing in a circle facing each other throughout the whole session.

- Group C also positioned themselves in a circle like Group B, but with some notable exceptions: one participant stood more or less still during the whole session while another participant was detached from the rest of the group.

[Insert Figure 2]

\section{Overall Movement Tendencies}

Next, the overall movement tendencies throughout the entire DJ mixes were considered. Quantity of motion (QoM) was used as a measure for the global activity level of each group. This has been calculated from the $Q o M_{\text {trajectory }}$ of an individual subject (one tracked trajectory) as the sum of the cumulative distance travelled for each marker in all directions (XYZ) divided by time:

$$
\text { QoM } M_{\text {trajectory }}=\frac{\sum_{n=2}^{N}\|\mathbf{p}(n)-\mathbf{p}(n-1)\|}{T}
$$

where $\mathbf{p}$ is a $3 \mathrm{D}$ position vector, $N$ is the total number of samples and $T$ is the total duration of the recording. Dividing by time gives an average velocity value (in $\mathrm{mm} / \mathrm{s}$ ) and also accounts for the slightly longer duration of DJ mix 2 (due to beat matching differences). From the set of individual data it is then possible to calculate the global QoM as the normalized sum of all the $Q o M_{\text {trajectory }}$ values:

$$
Q o M=\frac{\sum_{p=1}^{P} Q_{o} M_{\text {trajectory }}(p)}{P}
$$

where $P$ is the number of participants in each session.

Figure 3 displays the QoM of all the recordings, thus indicating the total amount of body movement for each group across the four tracks. Both the raw and smoothed movement data is presented, the latter is smoothed with a 10-second Savitzky-Golay filter in MATLAB. For reference, the audio wave plot also includes a 10-second smoothed root-mean-square 
(RMS) plot. The smoothed data was added due to the advantage of indicating a clear pattern without too much noise, which is valuable for comparison purposes between the groups.

Each group's QoM followed a similar trajectory, with relatively small fluctuations throughout the main part of the sessions and with some sudden and large changes that followed the structural and dynamical changes of the music. Even though the global horizontal movement distribution (as seen in Figure 2) was different for each group, the running QoM values showed a quite high level of consistency. A one-way analysis of variance (ANOVA) was conducted to compare the effect of groups to the QoM level for the four tracks. In the data set we included all the participants' QoM values for each of the four tracks as the dependent variable, which resulted in 116 QoM mean values. The one-way ANOVA showed that the effect of groups on QoM was not significant, $F(2,113)=1.132, p=.326, \eta_{p}{ }^{2}=.019$. This means that there were no statistically significant differences between the QoM means of Group A, Group B and Group C for the entire dance session.

The plots show fairly stable and flat QoM trajectories for the two control tracks, while there were clear trajectory changes for all groups during the break routines. The QoM was at its lowest for all groups during the two breakdown sections. As seen in Tables 3 and 4, paired-samples $t$-tests were conducted to compare the levels of QoM (a) before and after the break routine, and (b) to the breakdown and after the drop. This was carried out both to check differences on a global level (all participants) and on group level. Furthermore, we checked for differences between tracks and within tracks. The durations of the music segments we analysed in the $t$-tests were:

- Ladykiller: Pre-break (15s), breakdown (14s), and post-drop (15s)

- Icarus: Pre-break (15s), breakdown (19s), and post-drop (15s)

The $t$-tests show that there was a significant difference in how much the individuals and groups moved before the break routine and after the drop. The QoM was at its highest in the post-drop segment. The $t$-tests also show that the QoM level for the breakdown was significantly lower compared to after the drop. A one-way ANOVA was conducted to compare the effect of groups on the QoM level for the break routines. In the data set we included all the 
participants' QoM values for the two break routine segments as the dependent variable, which resulted in 229 QoM mean values. As determined by a one-way ANOVA, there were no statistically significant differences between the QoM means of Group A, Group B and Group $\mathrm{C}$ for how the groups moved to the break routine, $F(2,226)=0.066, p=.936, \eta_{p}{ }^{2}=.0006$.

[Insert Figure 3]

[Insert Table 3]

[Insert Table 4]

\section{Comparison of Groups and Music Segments}

Figure 4 summarizes the different QoM mean values for each group and for each music segment, and shows a clear relationship between QoM and music segments. The groups followed the same general movement pattern to the two break routines: a sudden and large decrease, followed by an increase in QoM. Across all participants, the break routine of Icarus resulted in the largest difference both when comparing the segments pre-break-drop (-168 $\mathrm{mm} / \mathrm{s})$ and breakdown-drop $(-299 \mathrm{~mm} / \mathrm{s})$. There were, however, minor variations between the groups (summarized in Table 3 and Table 4):

- Group A had the highest mean QoM value $(620 \mathrm{~mm} / \mathrm{s})$ across all music segments. The largest effect size (0.77) was found for this group in the comparison between the breakdown and drop of Icarus.

- Group B had the lowest global mean QoM (396 mm/s) measured throughout the entire dance session, as compared to Group A (398 mm/s) and Group C (408 mm/s). However, Group B had the largest comparative difference between both (a) pre-break and post-drop (-266 mm/s) and (b) breakdown and post-drop $(-380 \mathrm{~mm} / \mathrm{s})$. Group B also had the lowest QoM level $(221 \mathrm{~mm} / \mathrm{s})$ when in any of the break routines, and had the most statistically significant differences across all groups and music segments.

- Group C had the highest global QoM mean value $(408 \mathrm{~mm} / \mathrm{s})$ measured throughout the entire dance session. This was the only group for which the QoM differences between pre-break and post-drop for both Ladykiller and Icarus were not statistically significant. 
This was probably caused by a few of the participants moving very little and one of the participants being "detached" from the rest of the group. Accordingly, this group also had the smallest difference in their total group movement when comparing the QoM level before and after the break routines (Ladykiller: $-53.53 \mathrm{~mm} / \mathrm{s}$, Icarus: $-75.59 \mathrm{~mm} / \mathrm{s}$ ).

\section{[Insert Figure 4]}

\section{Vertical Position and Level of Synchronization to the Sound}

The vertical movement of dancers is often connected to one or more beat levels in the music. Figures 5 and 6 show plots of each subject's vertical displacement for the break routines of the two tracks Ladykiller and Icarus. A general observation is that the participants moved more profoundly up and down after the drop. This difference in the activity level of the groups could be seen from the QoM plots and $t$-tests performed. However, the vertical position plots show more details about the directivity and quality of the participants' movement patterns, and how these relate to the beat level of the music.

[Insert Figure 5]

[Insert Figure 6]

The break routines of Ladykiller and Icarus have several musical characteristics in common (please refer to Solberg, 2014, for a more detailed music analysis). Briefly summarized, these similarities include: (a) sudden and large changes in the frequency register, (b) removal and gradual reintroduction of musical features, and (c) a characteristic U-shaped amplitude profile with a sudden decrease at the breakdown, and then a gradual build towards the maximum amplitude at the drop (as seen in Figures 5, 6 and 7).

There are, however, a few differences between the musical passages of which the two break routines in Ladykiller and Icarus consist:

- The breakdown passage of Ladykiller keeps the rhythmical features of the track while in Icarus most of these features are removed. So even though the routine of Icarus is shorter (32s vs. 63s), it appears to have more contrasts than Ladykiller.

- The build-up effect is also different. Ladykiller uses a long, gradual low-pass filter opening of the main groove. Icarus, on the other hand, includes several intensifying 
musical features, such as the use of uplifters, drum rolls and a gradual reintroduction of the groove layers. As displayed in Figure 7, the sound is also louder in Icarus than in Ladykiller, both when measured as the mean amplitude and the global energy (using mirrms in the MIRtoolbox for MATLAB (Lartillot \& Toiviainen, 2007)).

- The drop is realized differently. In Icarus the drop is preceded by five syncopated snare drum hits and a loud, descending bass slide. In Ladykiller there is no distinct technique used other than the low-pass filter being completely opened when the main groove is reintroduced. The global energy level (RMS) is also higher after the drop for Icarus when comparing it to the pre-break, while Ladykiller's energy level is the same before and after the break routine.

\section{[Insert Figure 7]}

All of the three groups displayed a more systematic and pronounced vertical movement pattern after the drop. This was found when compared to the preceding sections, and also to the main groove before the breakdown, as shown in Figures 5 and 6. There were, however, differences in how the groups responded to the breakdown and build-up for the two tracks. For Ladykiller, the groups stayed closer to the beat and displayed a clearer vertical pattern during these sections. In particular, Group C stayed very close to the beat for the whole routine. The effects of the breakdown and build-up were more pronounced for Icarus (Figure 6), for which all groups danced with more fluid and less rhythmic body patterns.

To estimate how the participant's dancing corresponded to the musical beat level (quarter notes at 122-127 bpm), we performed a periodicity analysis. This was based on calculating the autocorrelation for each participant's motion trajectory for each temporal segment (using the function mcperiod in the MoCap Toolbox (Burger \& Toiviainen, 2013)), and selecting the first correlation peak as the estimate for the synchronized beat level. As expected, we found pulse-level synchronization (operationalised as being within $0.4-0.5 \mathrm{~s}$ ) mainly in the vertical dimension ( $\mathrm{Z}$ axis). Figure 8 shows a summary of the number of participants that synchronized vertically to the musical beat level for each segment. We here see that few participants synchronized to the pulse level during the breakdown and build-up sections, while the levels were fairly consistent (and with a little increase) for the pre-break 
and post-drop sections for both Ladykiller and Icarus. We also see from this figure that a higher number of participants synchronized to the beat level of Ladykiller than Icarus.

[Insert Figure 8]

\section{Transitions to Breakdown and Drop}

The relation between vertical movement patterns and the beat of the music is especially apparent in the close-up plots of the transitions between the pre-break segment and the breakdown, and between the build-up and drop. Figures 9 and 10 show 10-second segments of these two transitions, with five seconds before and after the breakdown and five seconds before and after the drop, respectively.

[Insert Figure 9]

[Insert Figure 10]

The close-up plots indicate the participants' level of synchronization before and after the break routine. All groups showed an improved level of synchronization right after both drops. The vertical patterns of all participants become more synchronized to the musical beat, and the patterns also grow bigger with more obvious and articulated vertical 'spikes'.

Some group differences are also noticeable in Figure 9 and 10. Groups A and B displayed a more collective vertical pattern for both Ladykiller and Icarus in comparison with Group C. Group B showed an improved level of synchronization between participants for Icarus compared to Ladykiller, which is apparent in how they prepare for the drop in Icarus as they seemed to be influenced by the five syncopated snare drum hits. Interestingly, Group B, who were facing each other throughout the entire session, were the most vertically aligned right before the drop of Icarus. Group C displayed the least obvious difference in the vertical pattern when comparing before and after the drop for both tracks. However, they showed a clearer and more synchronized up-and-down pattern after the drop of Ladykiller.

To also get an estimate of the spatial distribution of the vertical movement, an alternative to the global QoM, we calculated the standard deviation of the vertical position for each segment. The results are summarized in Table 5, and show a clear increase in vertical activity from pre-break to post-drop for both Ladykiller and Icarus. The difference in standard 
deviation between pre-break and post-drop is also larger for Icarus than for Ladykiller, $10.14 \mathrm{~mm}$ vs. $3.99 \mathrm{~mm}$ respectively.

[Insert Table 5]

\section{Gender}

To check for the effect of gender, we conducted an independent-samples $t$-test to compare QoM levels across gender for the entire dance session. With the QoM segments as dependent variable and gender as independent variable, we found a significant difference in the overall QoM levels for female $(M=349, S D=84.25)$ and male $(M=456, S D=207)$ conditions; $t$ (71.656)=-3.597, $p=.001, d=0.68$. This showed that the male participants had a higher level of QoM throughout the entire dance session.

\section{Discussion}

The analyses confirmed that the break routine in EDM has a large impact on the participants' body movements. First, the overall movement patterns were quite similar throughout each session for all groups. The activity changes were to a large extent related to the structural and textural changes occurring in the music in the break routines: the lowest QoM level occurred during the breakdowns and the highest QoM level in connection to the drops. There was a statistically significant difference in QoM levels when comparing the segments before and after the break routines. These findings concur with existing research suggesting that we move more easily to music with an obvious beat and strong rhythmic focus and that we move with more active and complex body movement to music with a high energy level (Burger, Saarikallio, et al., 2013; Burger, Thompson, et al., 2013). Our results also confirm the importance of the bass drum (Van Dyck et al., 2013), since the removal and reintroduction of the bass drum is one of the core features of a break routine.

\section{Influence of Specific Musical Features in the Break Routine}

The data also showed that the observed vertical position patterns of all the participants were more systematic and obvious after the drops as opposed to the breakdowns, build-ups and the main grooves. Here the vertical movement patterns grew larger and became 
more synchronized to the musical beat. Additionally, an improved level of interpersonal synchronization was established after the drop by the participants for both tracks. This result is consistent with the idea that we embody the musical beat with vertical movements and that our periodic movements are related to beat level (Burger et al., 2014). Furthermore, it supports existing research on interpersonal synchronization, suggesting that music leads to people moving more effectively and energetic (McNeill, 1995), in addition to moving more together with others (De Bruyn et al., 2008). However, to our knowledge, little research has been done on how such large textural, structural and dynamical changes influence group behaviour. Our results imply that the break routine re-energizes people's dance movements, and that such breaks actually improves the level of interpersonal synchronization and increases the total level of activity. This is particularly interesting since the musical content (the groove) before and after the break routine is the same.

A comparison of the number of participants that were locked to the beat period of the music for each track, indicates a higher level of synchronization for Ladykiller than Icarus. Another interesting observation is how the vertical position data showed that the participants moved more to the break routine of Icarus than that of Ladykiller. We suggest that these differences are related to the sonic qualities and structural properties of the two tracks. Ladykiller keeps more of the rhythmic features throughout the break routine, while Icarus' break routine comprises a larger contrast to the main groove than Ladykiller. This might explain why the participants find it easier to synchronize to the quarter note level of Ladykiller. However, Icarus includes an increase in global energy (RMS) after the drop and use several intensifying features, such as the uplifter effect and drum-rolls. This could then be the reason for why the difference in the standard deviation of the vertical position between pre-break and post-drop was larger for Icarus than for Ladykiller (10.14 mm vs. $3.99 \mathrm{~mm}$ ).

The removal and reintroduction of the rhythmic framework in Icarus, and especially the bass and the bass drum, is a key feature, and might therefore function as an effective synchronization tool due to its large textural and dynamic contrasts. This is in accordance with the findings of Van Dyck et al. (2013) which suggest that the presence and dynamics of the bass drum both influence and improve the level of body movement and entrainment. 


\section{Influence of Horizontal Position}

Even though the groups responded similarly to the music at large, the horizontal position patterns revealed differences in the groups' self-formation and synchronization. Group B was the most "static," dancing in a circle facing each other throughout the entire session. Interestingly, this group displayed the largest (and statistically significant) difference in QoM before and after the break routines. This group was also the only group to collectively prepare for the drop of Icarus, as seen in their vertical movement pattern.

Group C, in comparison, had the highest global QoM across the whole session, but only had a marginally (and not statistically significant) higher QoM level after the drop compared to before the break routine. The vertical movement pattern also indicated that Group C was the least synchronized and lacked a clear group identity. This group was also the one that danced the least "together," with a few subjects standing relatively still while another subject danced alone next to the others. These results support the idea that people synchronize better when they see each other (Desmet et al., 2010).

\section{Concluding Remarks and Further Research}

The present study has explored how individuals in groups interact and synchronize to each other and to EDM features in a club-like environment. The data supports the idea that the break routine influences the global activity level and the vertical movement pattern of participants, re-energizes the dance movements of a group and efficiently leads to entrainment of a whole group of dancing people. In addition to the influential factors mentioned above, there are a number of other elements that it would be interesting to consider in future studies.

One potential factor is that of familiarity with the music examples. Measurement of familiarity was not carried out in this specific study, since the same four tracks scored very low on familiarity in our previous dance study (Solberg \& Jensenius, 2016b). None of the tracks used have been listed on any of the Billboard (Billboard.com, 2016) charts or the Norwegian equivalent "VG-lista" (VG-lista, 2016) in recent years, so we can assume a low familiarity also in this study.

A second factor to be considered is the effect of gender. Analysing the general 
QoM levels, we found that the male participants moved significantly more than the female participants. This contradicts previous studies, which have reported that women tend to move more than men (Passmore \& French, 2001; Van Dyck et al., 2013). One could argue that men are taller than women, on average, and would therefore necessarily also have larger movements, but the difference was larger than such a normal variation could account for. In future studies it would be interesting to more systematically study gender differences and control for other influential factors, such as personality, music preference, music training and dancing habits.

A third factor that was not taken into consideration in this study was food intake, which may be argued to have an effect on the dancing performance. To create a social and relaxing atmosphere for the participants, pizza and non-alcoholic beverages were provided in the canteen area next to the location of the experiment. This was a method for attracting participants, and also served as an ice-breaker, decreasing awkwardness during the dancing sessions. The participants ate one to two pizza slices each, and considering the fairly modest dancing activity, we would not assume this to have a major influence on the results.

A fourth factor is that of group and sample size. In our previous study we used a group of 15 participants, but experienced some tracking difficulties (Solberg \& Jensenius, 2016b). Now we managed to get good data with groups of 9-10 people, which is still considerably more than other comparable studies. We were only able to record three groups, however, so the total number of participants is lower than that of other studies, such as Van Dyck et al. (2013). For future studies it would be interesting to compare both more and larger groups.

One important choice we made was to use a pre-recorded DJ mix as opposed to using a live DJ that would interact with the crowd. This was because the focus here was on the interaction between the music and the other participants. A natural continuation of this research will be to study the interaction in a live DJ setting.

Finally, even though we strived to make the study as ecologically valid as possible, there are obviously some constraints posed by carrying out a controlled experiment in a lab setting. The physical limitations of the space is one, combined with the "surveillance" feeling 
that such a setup necessarily creates. For that reason we are eager to carry out a study in a real club environment, in which we could study dancing over a longer period of time, include more musical examples and test the responses to several different break routines. For such a study it would probably be necessary to move beyond a camera-based setup, and rather use a set of accelerometers, like the AX3 devices we tested briefly in this study. Such sensors would not be able to provide accurate position information, but would still be useful for recording continuous movement data aligned with the music. This could hopefully cast further light on the pleasures of dancing together to music. 


\section{Acknowledgements}

The authors would like to thank all the students that took part in the study, as well as Diana Kayser, Kristian Nymoen and Minho Song for their assistance in setting up and running the experiments. 
References

Billboard.com. (2016). Billboard charts. Retrieved March 13, 2017, from http://www.billboard.com/chartsid-chart-category-pop

Brown, S., Merker, B., \& Wallin, N. L. (2000). An introduction to evolutionary musicology. In S. Brown, B. Merker, \& N. L. Wallin (Eds.), The origins of music (pp. 3-24). Cambridge, Mass.: MIT press.

Burger, B. (2013). Move the way you feel: Effects of musical features, perceived emotions, and personality on music-induced movement. Doctoral dissertation, University of Jyväskylä, Jyväskylä.

Burger, B., Saarikallio, S., Luck, G., Thompson, M. R., \& Toiviainen, P. (2013). Relationships between perceived emotions in music and music-induced movement. Music Perception, 30(5), 517-533.

Burger, B., Thompson, M., Luck, G., Saarikallio, S., \& Toiviainen, P. (2014). Hunting for the beat in the body: On period and phase locking in music-induced movement. Frontiers in Human Neuroscience, 8 (November), 903. doi: 10.3389/fnhum.2014.00903

Burger, B., Thompson, M. R., Luck, G., Saarikallio, S., \& Toiviainen, P. (2012). Music moves us: Beat-related musical features influence regularity of music-induced movement. In E. Cambouropoulos, C. Tsougras, P. Mavromatis, \& K. Pastiadis (Eds.), Proceedings of the 12th International Conference on Music Perception and Cognition and the 8th Triennial Conference of the European Society for the Cognitive Sciences of Music (pp. 183-187). Thessaloniki, Greece.

Burger, B., Thompson, M. R., Luck, G., Saarikallio, S., \& Toiviainen, P. (2013). Influences of rhythm- and timbre-related musical features on characteristics of music-induced movement. Frontiers in Psychology, 4, 183. doi: 10.3389/fpsyg.2013.00183

Burger, B., Thompson, M. R., Saarikallio, S., Luck, G., \& Toiviainen, P. (2010). Influence of musical features on characteristics of music-induced movements. In S. M. Demorest, S. J. Morrison, \& P. S. Campbell (Eds.), Proceedings of the 11th International Conference on Music Perception and Cognition (pp. 425-428). Seattle, Washington, USA. 
Burger, B., \& Toiviainen, P. (2013). MoCap toolbox - A Matlab toolbox for computational analysis of movement data. In R. Bresin (Ed.), Proceedings of the 10th Sound and Music Computing Conference (pp. 172-178). Berlin: Logos Verlag.

Butler, M. J. (2006). Unlocking the groove: Rhythm, meter, and musical design in electronic dance music. Bloomington, Ind.: Indiana University Press.

Chen, J., Penhune, V., \& Zatorre, R. (2008). Listening to musical rhythms recruits motor regions of the brain. Cerebral Cortex, 18(12), 2844-2854.

Clayton, M., Dueck, B., \& Leante, L. (2013). Experience and meaning in music performance. New York: Oxford University Press.

Codrons, E., Bernardi, N. F., Vandoni, M., \& Bernardi, L. (2014). Spontaneous group synchronization of movements and respiratory rhythms. PLoS ONE, 9(9), e107538. doi: 10.1371/journal.pone.0107538

Cross, I. (2001). Music, mind, and evolution. Psychology of Music, 29(1), 95-102.

Cross, I. (2008). Musicality and the human capacity for culture. Musicae Scientiae, Special Issue: Narrative in Music and Interaction, 147-167.

De Bruyn, L., Leman, M., \& Moelants, D. (2008). Quantifying children's embodiment of musical rhythm in individual and group settings. In K. Miyazaki, Y. Hiraga, M. Adachi, Y. Nakajima, \& M. Tsuzaki (Eds.), Proceedings of the 10th International Conference on Music Perception and Cognition (pp. 662-667). Sapporo, Japan.

Demos, A. P., Chaffin, R., Begosh, K. T., Daniels, J. R., \& Marsh, K. L. (2012). Rocking to the beat: Effects of music and partner's movements on spontaneous interpersonal coordination. Journal of Experimental Psychology, General, 141(1), 49-53.

Desmet, F., Leman, M., Lesaffre, M., \& de Bruyn, L. (2010). Statistical analysis of human body movement and group interactions in response to music. Studies in Classification, Data Analysis, and Knowledge Organization, 399-408.

Drake, C., Penel, A., \& Bigand, E. (2000). Tapping in time with mechanically and expressively performed music. Music Perception, 18(1), 1-23.

Eerola, T., Luck, G., \& Toiviainen, P. (2006). An investigation of pre-schoolers' corporeal synchronization with music. In M. Baroni, A. R. Addessi, R. Caterina, \& M. Costa 
(Eds.), Proceedings of the 9th International Conference on Music Perception \& Cognition (pp. 472-476). Bologna, Italy.

Ellamil, M., Berson, J., Wong, J., Buckley, L., \& Margulies, D. S. (2016). One in the dance: Musical correlates of group synchrony in a real-world club environment. PLoS ONE, 11(10), e0164783. doi: 10.1371/journal.pone.0164783

Freeman, W. J. (2000). A neurobiological role of music in social bonding. In N. L. Wallin, B. Merker, \& S. Brown (Eds.), The origins of music (pp. 411-424). Cambridge, Mass.: MIT Press.

Godøy, R. I., \& Leman, M. (Eds.). (2010). Musical gestures: Sound, movement, and meaning. New York: Routledge.

Grahn, J. A., \& Brett, M. (2007). Rhythm and beat perception in motor areas of the brain. Journal of Cognitive Neuroscience, 19(5), 893-906.

Hove, M. J., \& Risen, J. L. (2009). It's all in the timing: Interpersonal synchrony increases affiliation. Social Cognition, 27(6), 949-960.

Janata, P., Tomic, S. T., \& Haberman, J. M. (2012). Sensorimotor coupling in music and the psychology of the groove. Journal of Experimental Psychology: General, 141(1), $54-75$.

Kirschner, S., \& Tomasello, M. (2009). Joint drumming: Social context facilitates synchronization in preschool children. Journal of Experimental Child Psychology, 102(3), 299-314.

Lartillot, O., \& Toiviainen, P. (2007). A Matlab toolbox for musical feature extraction from audio. In Proceedings of the 10th International Conference on Digital Audio Effects (pp. 237-244). Bordeaux, France.

Leman, M. (2008). Embodied music cognition and mediation technology. Cambridge, Mass.: MIT Press.

Leman, M., \& Naveda, L. (2010). Basic gestures as spatiotemporal reference frames for repetitive dance/music patterns in samba and charleston. Music Perception, 28(1), 71-91.

Madeon. (2012). Icarus (Extended mix). [Single]. France: Popcultur. 
Marsh, K. L., Richardson, M. J., \& Schmidt, R. C. (2009). Social connection through joint action and interpersonal coordination. Topics in Cognitive Science, 1(2), 320-339.

McNeill, W. (1995). Keeping together in time: Dance and drill in human history. Cambridge, Mass.: Harvard University Press.

Merker, B. H., Madison, G. S., \& Eckerdal, P. (2009). On the role and origin of isochrony in human rhythmic entrainment. Cortex, 45(1), 4-17.

NUAGE. (2014). Unlock down (Original mix) [Single]. Russia: Electronica Records.

Overy, K., \& Molnar-Szakacs, I. (2009). Being together in time: Musical experience and the mirror neuron system. Music Perception, 26(5), 489-504.

Passmore, A. E., \& French, D. (2001). The development and administration of a measure to assess adolescents' leisure participation. Adolescence, 36(141), 66-75.

Phillips-Silver, J., Aktipis, C. A., \& Bryant, G. A. (2010). The ecology of entrainment: Foundations of coordinated rhythmic movement. Music Perception, 28(1), 3-14.

Phillips-Silver, J., \& Trainor, L. J. (2007). Hearing what the body feels: Auditory encoding of rhythmic movement. Cognition, 105(3), 533-546.

Pressing, J. (2002). Black Atlantic rhythm: Its computational and transcultural foundation. Music Perception, 19(3), 285-310.

Reddish, P., Bulbulia, J., \& Fischer, R. (2014). Does synchrony promote generalized prosociality? Religion Brain \& Behaviour, 4(1), 3-19.

Repp, B. H. (2005). Sensorimotor synchronization: A review of the tapping literature. Psychonomic Bulletin \& Review, 12(6), 969-992.

Repp, B. H., \& Su, Y.-H. (2013). Sensorimotor synchronization: A review of recent research (2006-2012). Psychonomic Bulletin \& Review, 20(3), 403-452.

Rhode and Brown feat. Schegg. (2013). Joyride [Single]. Germany: Toy Tonics.

Snyder, J., \& Krumhansl, C. L. (2001). Tapping to ragtime: Cues to pulse finding. Music Perception, 18(4), 455-489.

Solberg, R. T. (2014). "Waiting for the bass to drop": Correlations between intense emotional experiences and production techniques in build-up and drop sections of electronic dance music. Dancecult: Journal of Electronic Dance Music Culture, 6(1), 61-82. 
Solberg, R. T., \& Jensenius, A. R. (2016a). Optical or inertial? Evaluation of two motion capture systems for studies of dancing to electronic dance music. In Proceedings of the Sound and Music Computing Conference (pp. 469-474). Berlin: Logos Verlag.

Solberg, R. T., \& Jensenius, A. R. (2016b). Pleasurable and intersubjectively embodied experiences of electronic dance music. Empirical Musicology Review, 11(3-4), 301-318. doi: 10.18061/emr.v11i3-4

Song, M.-H., \& Godøy, R. I. (2016). How fast is your body motion? Determining a sufficient frame rate for an optical motion tracking system using passive markers. PLoS ONE, 11(3), e0150993. doi: 10.1371/journal.pone.0150993

Stupacher, J., Hove, M. J., Novembre, G., Schültz-Bosbach, S., \& Keller, P. E. (2013). Musical groove modulates motor cortex excitability: A TMS investigation. Brain and Cognition, 82(2), 127-136.

Tarr, B., Launay, J., \& Dunbar, R. I. M. (2016). Silent disco: Dancing in synchrony leads to elevated pain thresholds and social closeness. Evolution and Human Behaviour, 37(5), 343-349.

Toiviainen, P., Luck, G., \& Thompson, M. R. (2010). Embodied meter: Hierarchical eigenmodes in music-induced movement. Music Perception, 28(1), 59-70.

Van Dyck, E., Moelants, D., Demey, M., Deweppe, A., Coussement, P., \& Leman, M. (2013). The impact of the bass drum on human dance movement. Music Perception, 30(4), 349-359.

Vanilla Ace. (2014). Ladykiller (Original mix) [Single]. UK: Erase Records.

VG-lista. (2016). Vg-lista. Retrieved March 13, 2017, from http: / / i ista • vg • no/

Wiltermuth, S. S., \& Heath, C. (2009). Synchrony and cooperation. Psychological Science, 20(1), 1-5.

Woolhouse, M. H., Tidhar, D., \& Cross, I. (2016). Effects on inter-personal memory of dancing in time with others. Frontiers in Psychology, 7, 167. doi: 10.3389/fpsyg.2016.00167

Zentner, M., \& Eerola, T. (2010). Rhythmic engagement with music in infancy. Proceedings of the National Academy of Sciences, 107(13), 5768-5773. 
Table 1

Overview and characteristics of the four tracks in DJ mix 1 used for Groups A and C.

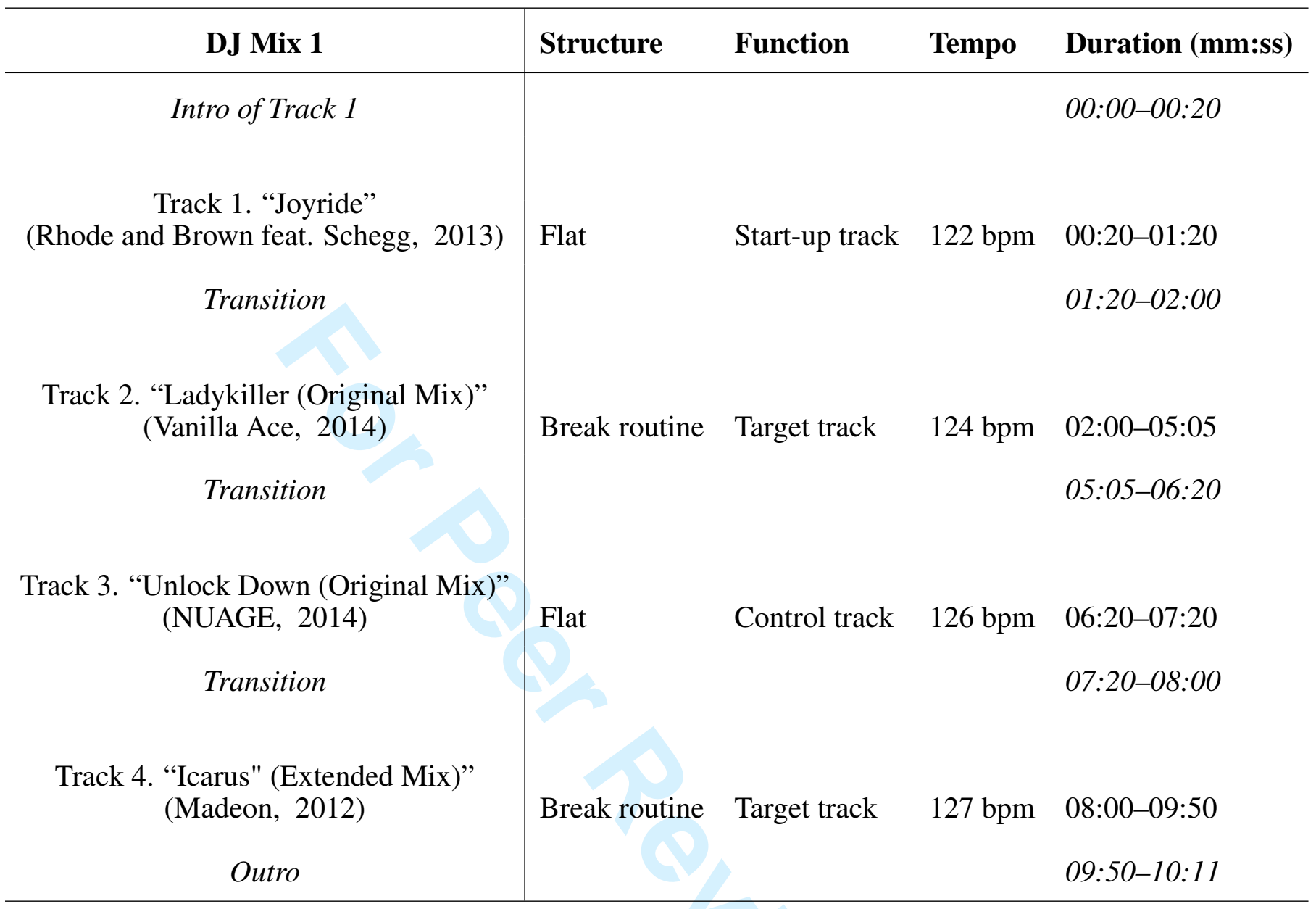




\section{Table 2}

Overview and characteristics of the four tracks in DJ mix 2 used for Group B.

\begin{tabular}{|c|c|c|c|c|}
\hline DJ Mix 2 & Structure & Function & Tempo & Duration (mm:ss) \\
\hline Intro of Track 1 & & & & $00: 00-00: 20$ \\
\hline $\begin{array}{c}\text { Track 1. "Joyride" } \\
\text { (Rhode and Brown feat. Schegg, 2013) } \\
\text { Transition }\end{array}$ & Flat & Start-up track & 122 bpm & $\begin{array}{l}00: 20-01: 20 \\
01: 20-02: 30\end{array}$ \\
\hline $\begin{array}{c}\text { Track 2. "Icarus (Extended Mix)" } \\
\text { (Madeon, 2012) } \\
\text { Transition }\end{array}$ & Break routine & Target track & $124 \mathrm{bpm}$ & $\begin{array}{l}02: 30-04: 30 \\
04: 30-05: 50\end{array}$ \\
\hline $\begin{array}{c}\text { Track 3. "Unlock Down (Original Mix)" } \\
\text { (NUAGE, 2014) } \\
\text { Transition }\end{array}$ & Flat & Control track & $126 \mathrm{bpm}$ & $\begin{array}{l}05: 45-06: 45 \\
06: 45-07: 20\end{array}$ \\
\hline $\begin{array}{c}\text { Track 4. "Ladykiller (Original Mix)" } \\
\text { (Vanilla Ace, 2014) } \\
\text { Outro }\end{array}$ & Break routine & Target track & $127 \mathrm{bpm}$ & $\begin{array}{l}07: 20-10: 02 \\
10: 02-10: 19\end{array}$ \\
\hline
\end{tabular}


Table 3

Mean QoM values $(\mathrm{mm} / \mathrm{s})$ - with standard deviation in parentheses - for all participants and groups in the various pre-break and post-drop segments. The differences in QoM between pre-break and post-drop are also presented, as well as statistical measures.

\begin{tabular}{|c|c|c|c|c|c|c|c|}
\hline & Pre-break & Post-drop & Diff. & $t$ & $d f$ & $p$ & $r^{2}$ \\
\hline \multicolumn{8}{|l|}{ Global $(n=29)$} \\
\hline Both tracks & $407(163)$ & $559(214)$ & -152 & -8.461 & 56 & $<.001$ & .14 \\
\hline Ladykiller & $405(166)$ & $543(216)$ & -138 & -6.07 & 28 & $<.001$ & .11 \\
\hline Icarus & $408(162)$ & $575(214)$ & -167 & -5.92 & 27 & $<.001$ & .07 \\
\hline \multicolumn{8}{|l|}{ Group $A(n=9)$} \\
\hline Both tracks & 403 (106) & $586(137)$ & -182 & -5.78 & 16 & $<.001$ & .36 \\
\hline Ladykiller & $350(101)$ & $555(146)$ & -205 & -5.71 & 8 & $<.001$ & .40 \\
\hline Icarus & $463(78)$ & $620(125)$ & -157 & -2.86 & 7 & .0024 & .36 \\
\hline \multicolumn{8}{|c|}{ Group $B(n=10)$} \\
\hline Both tracks & $370(121)$ & $584(183)$ & -214 & -7.37 & 19 & $<.001$ & .32 \\
\hline Ladykiller & 406 (139) & $568(193)$ & -162 & -3.98 & 9 & .003 & .19 \\
\hline Icarus & $335(94)$ & $601(180)$ & -266 & -7.38 & 9 & $<.001$ & .46 \\
\hline \multicolumn{8}{|c|}{ Group $C(n=10)$} \\
\hline Both tracks & $446(226)$ & $510(286)$ & -64.56 & -2.85 & 19 & .01 & .02 \\
\hline Ladykiller & $453(229)$ & $506(294)$ & -53.53 & -2.08 & 9 & .068 & .01 \\
\hline Icarus & $438(236)$ & $514(293)$ & -75.59 & -1.97 & 9 & .081 & .02 \\
\hline
\end{tabular}


GROUP SYNCHRONIZATION TO EDM

Table 4

Mean QoM values $(\mathrm{mm} / \mathrm{s})$ - with standard deviation in parentheses - for all participants and groups in the various breakdown and post-drop segments. The differences in QoM between breakdown and post-drop are also presented, as well as statistical measures.

\begin{tabular}{|c|c|c|c|c|c|c|c|}
\hline & Breakdown & Post-drop & Diff. & $t$ & $d f$ & $p$ & $r^{2}$ \\
\hline \multicolumn{8}{|l|}{ Global $(n=29)$} \\
\hline Both tracks & $287(165)$ & $559(214)$ & -272 & -11.61 & 56 & $<.001$ & .34 \\
\hline Ladykiller & 297 (153) & $543(216)$ & -245 & -8.25 & 28 & $<.001$ & .30 \\
\hline Icarus & $276(178)$ & $575(214)$ & -299 & -8.27 & 27 & $<.001$ & .37 \\
\hline \multicolumn{8}{|c|}{ Group $A(n=9)$} \\
\hline Both tracks & 290 (119) & $586(137)$ & -295 & -7.03 & 16 & $<.001$ & .57 \\
\hline Ladykiller & $320(151)$ & $555(146)$ & -236 & -3.69 & 8 & .006 & .39 \\
\hline Icarus & $257(61)$ & $620(125)$ & -362 & -4.78 & 7 & $<.001$ & .77 \\
\hline \multicolumn{8}{|c|}{ Group $B(n=10)$} \\
\hline Both tracks & $256(105)$ & $584(183)$ & -328 & -9.23 & 19 & $<.001$ & .55 \\
\hline Ladykiller & $291(121)$ & $568(193)$ & -277 & -5.19 & 9 & .001 & .42 \\
\hline Icarus & $221(76.38)$ & $601(180)$ & -380 & -8.70 & 9 & $<.001$ & .65 \\
\hline \multicolumn{8}{|c|}{ Group $C(n=10)$} \\
\hline Both tracks & $316(235)$ & $510(286)$ & -195 & -4.93 & 19 & $<.001$ & .12 \\
\hline Ladykiller & $284(194)$ & $506(294)$ & -223 & -5.39 & 9 & $<.001$ & .17 \\
\hline Icarus & 347 (277) & $514(293)$ & -167 & -2.43 & 9 & .038 & .08 \\
\hline
\end{tabular}


Table 5

Standard deviations (in millimetres) of the vertical position for the pre-break and post-drop segments for Ladykiller and Icarus.

\begin{tabular}{c|c|c}
\hline Music segment & Pre-break (mm) & Post-drop (mm) \\
\hline Ladykiller & 19.36 & 23.35 \\
Icarus & 28.69 & 38.83 \\
\hline
\end{tabular}




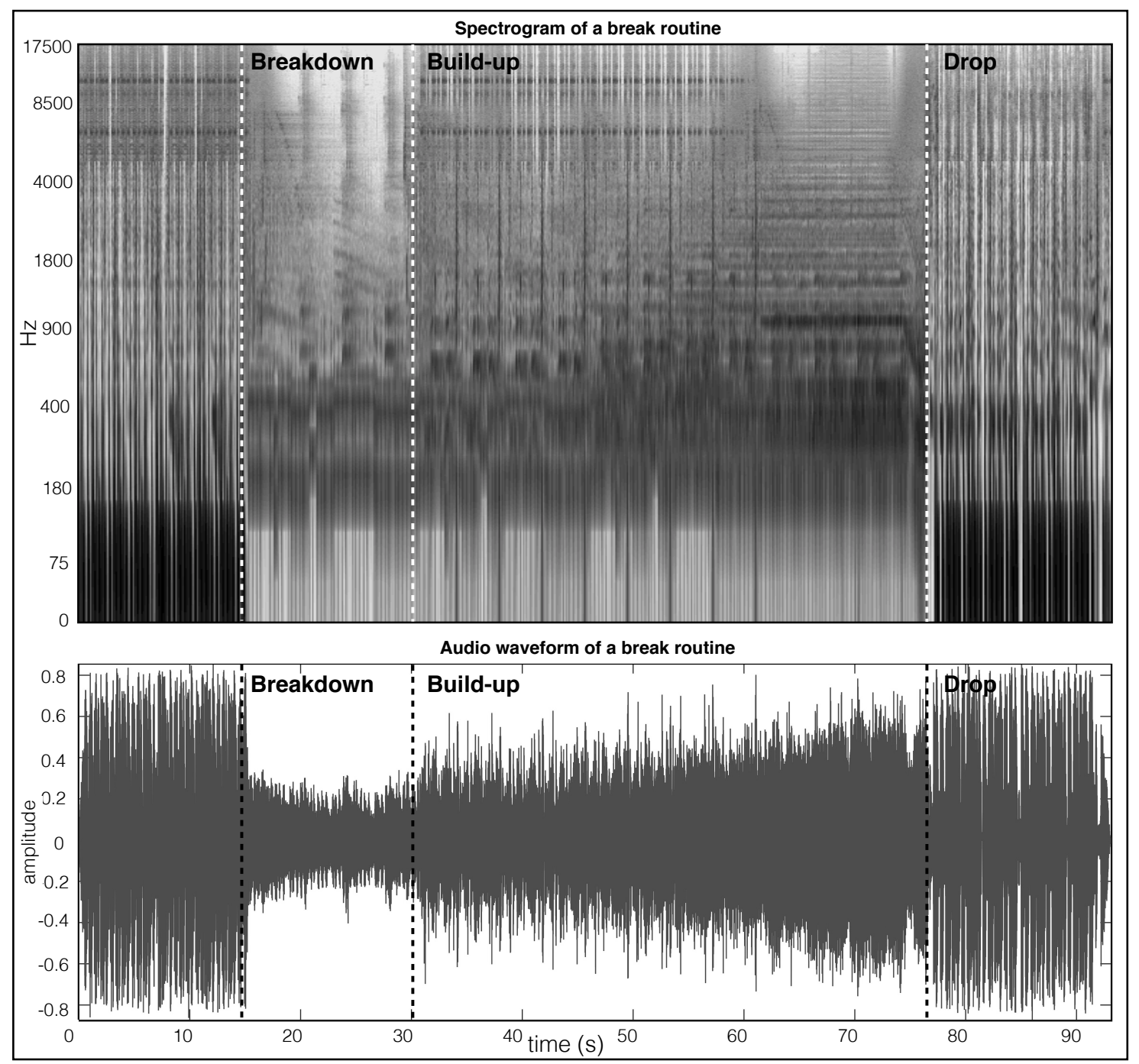

Figure 1. A spectrogram of a break routine consisting of three parts: breakdown, build-up and drop. The horizontal axis indicates time while the frequency components (in $\mathrm{Hz}$ ) is found in the vertical axis. The intensity of the colour indicates the level of energy in the different frequency regions. This is a logarithmic dBV spectrogram of window size 1024, which provides a useful balance between the temporal and spectral features in musical styles of a relatively fast tempo, such as EDM. Aligned with the spectrogram is the audio waveform of the break routine. 

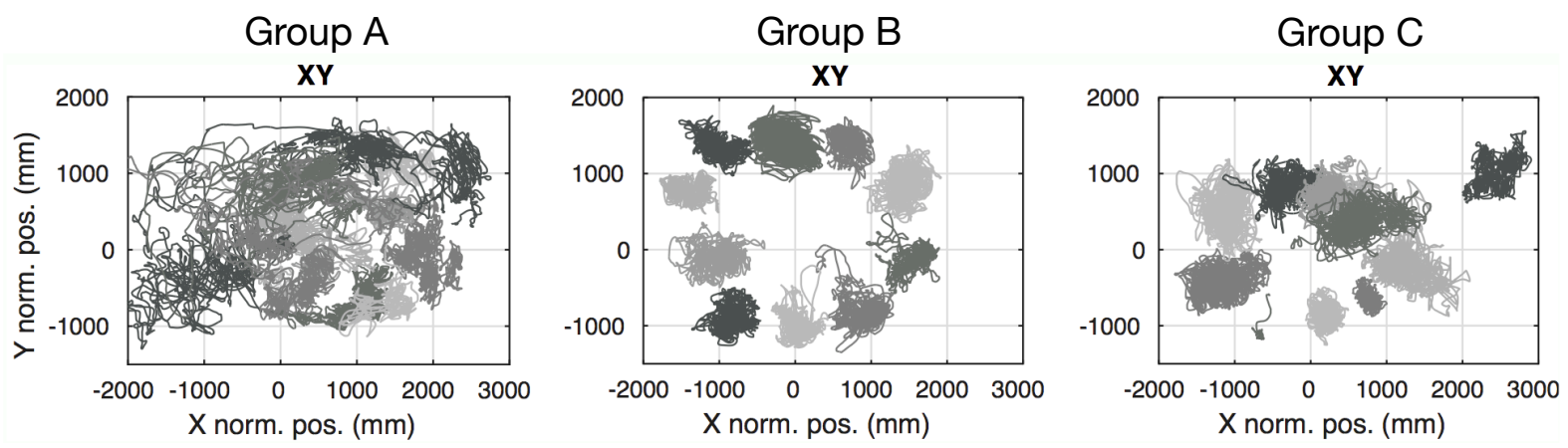

Figure 2. XY plot of the three groups, which shows the horizontal movement pattern (bird's eye perspective) of the participants. The plots cover the lab's capture space $(3500 \times 5000 \mathrm{~mm})$ and include data from the whole dance session (10 $\mathrm{min})$. 


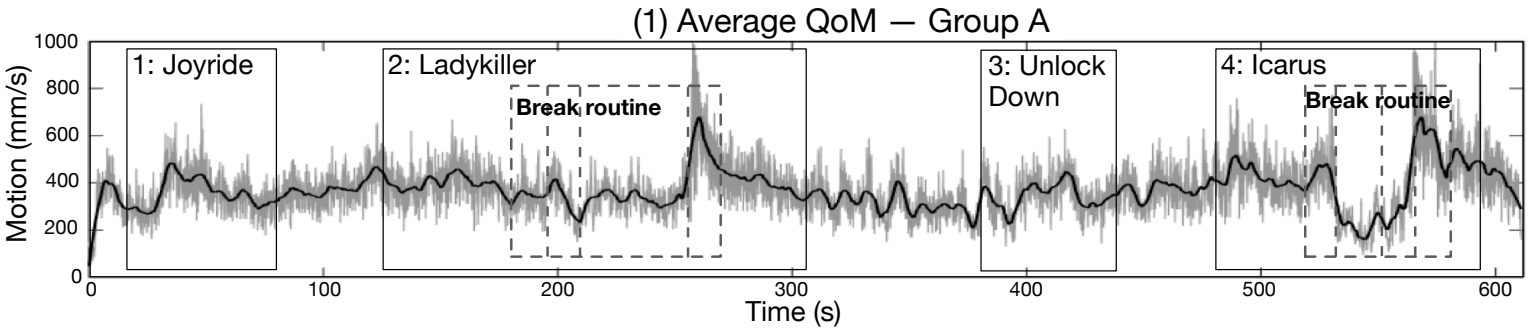

(2) Average QoM - Group C

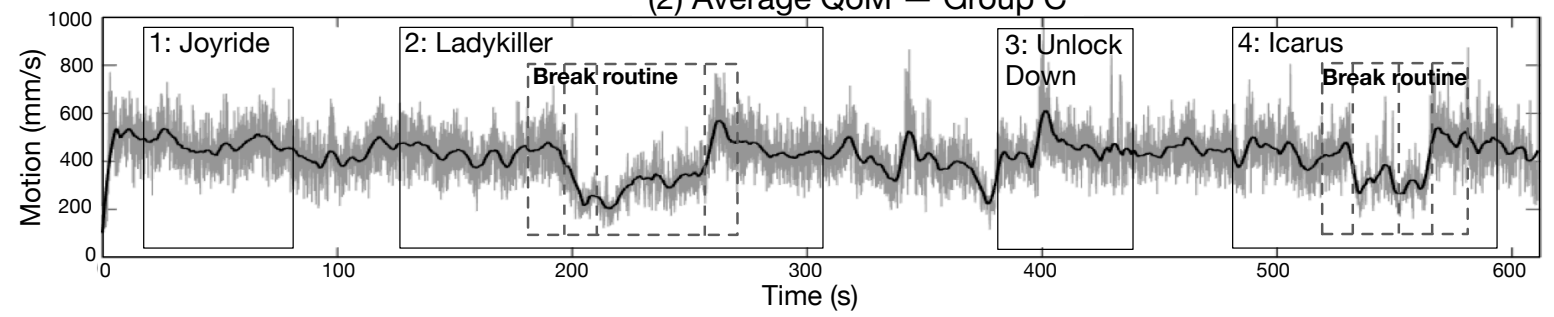

(3) Audio - DJ mix 1

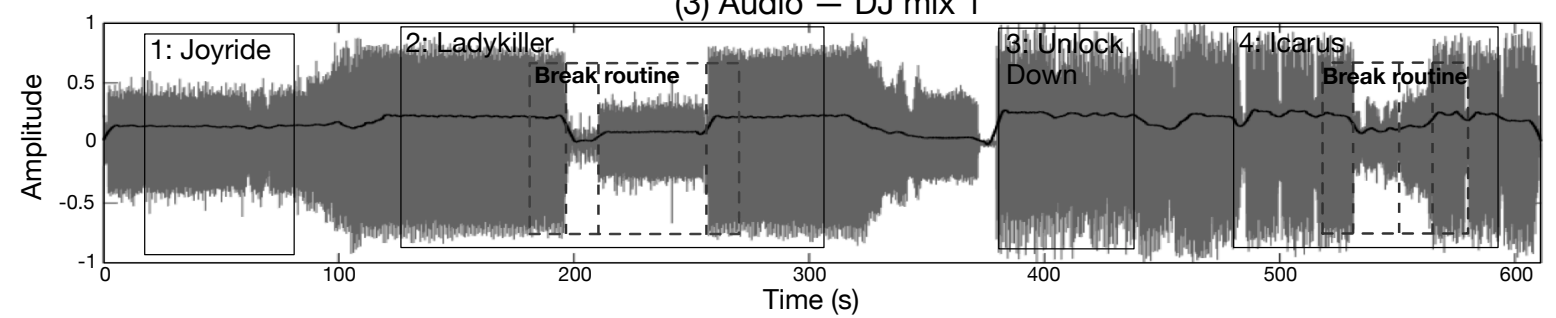

(4) Average QoM - Group B

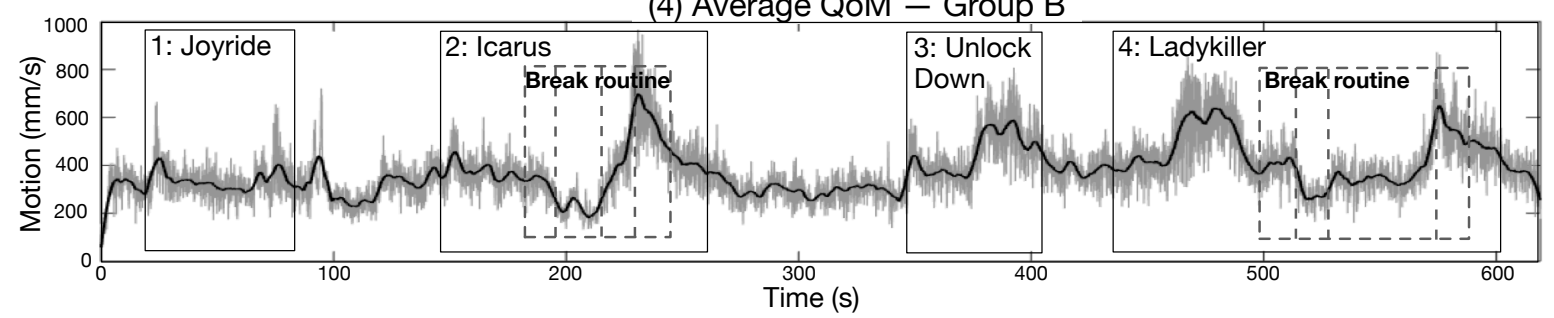

(5) Audio - DJ mix 2

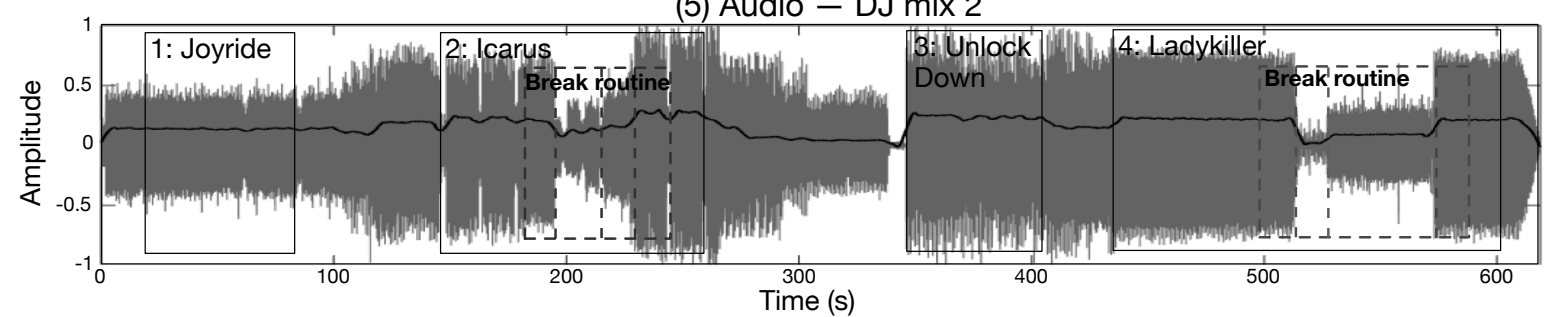

Figure 3. Plots 1, 2 and 4 show the raw and low-pass filtered quantity of motion (QoM) for all subjects in Group A, B and C for the entire dance session (10min). Plots 3 and 5 display the audio amplitude and low-pass filtered RMS of the audio track. The black squares mark the main segment of each track while the stippled squares highlight the two break routines occurring during the DJ mix. 
Mean QoM values for music segments

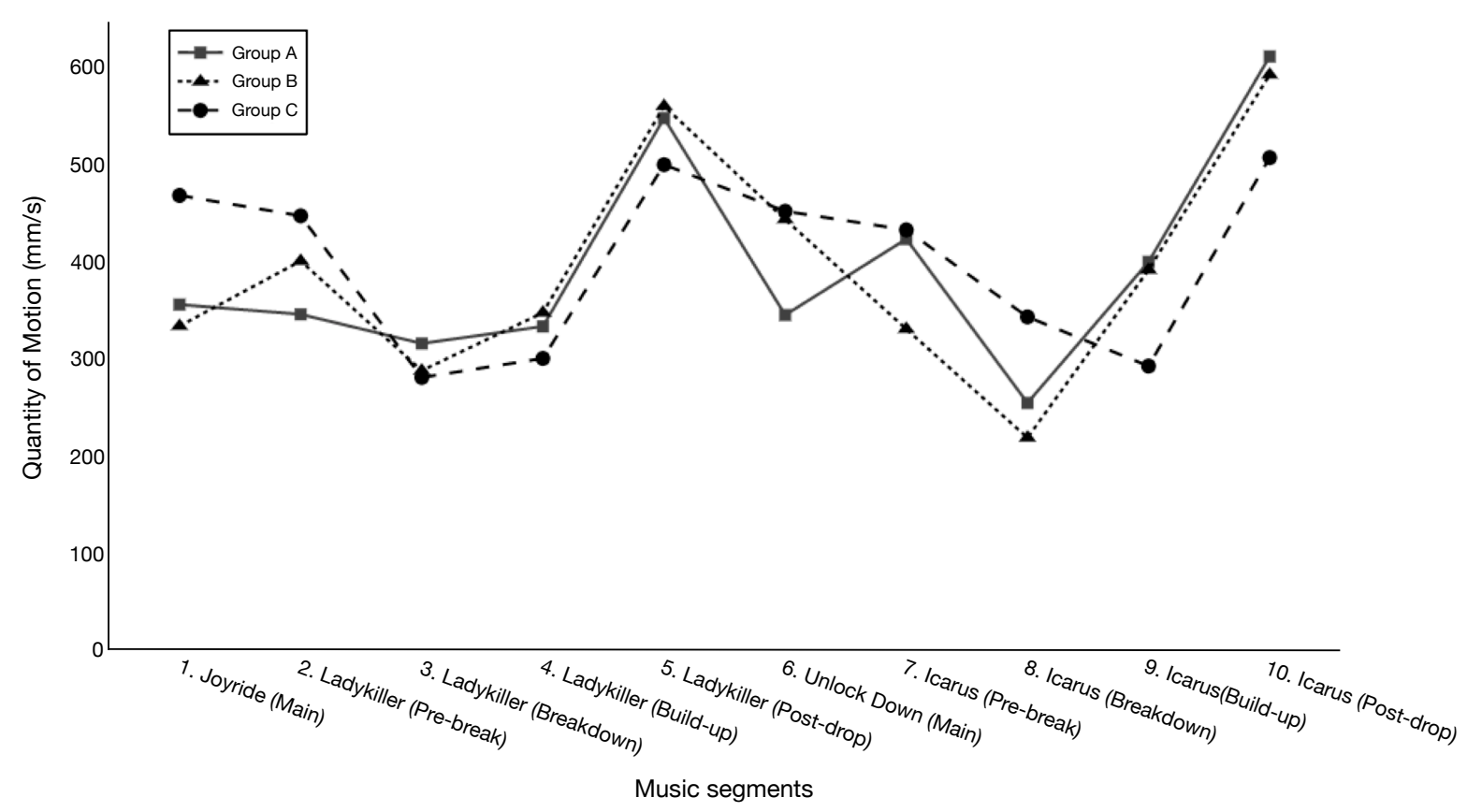

Figure 4. Mean QoM values $(\mathrm{mm} / \mathrm{s})$ for each of the groups for each of the different music segments in the DJ mixes. 
Figure 5. The groups' vertical position (mm) for the Ladykiller break routine. The corresponding audio envelope of the break routine is presented below. 
Figure 6. The groups' vertical position (mm) for the Icarus break routine. The corresponding audio envelope of the break routine is presented below. 
Mean values for audio amplitude

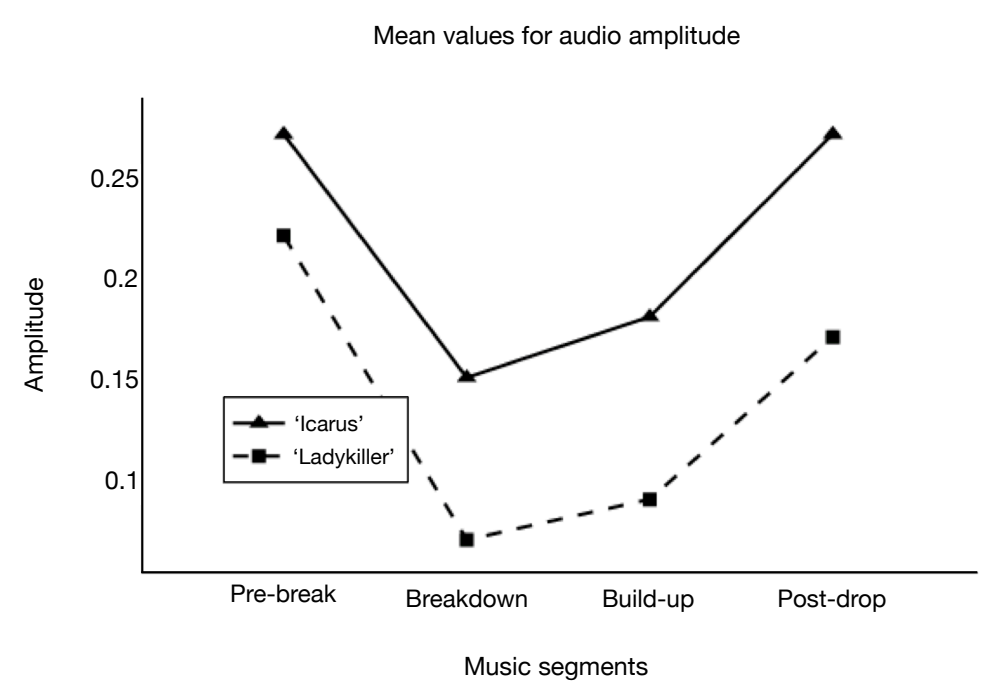

Mean values for global energy (RMS)

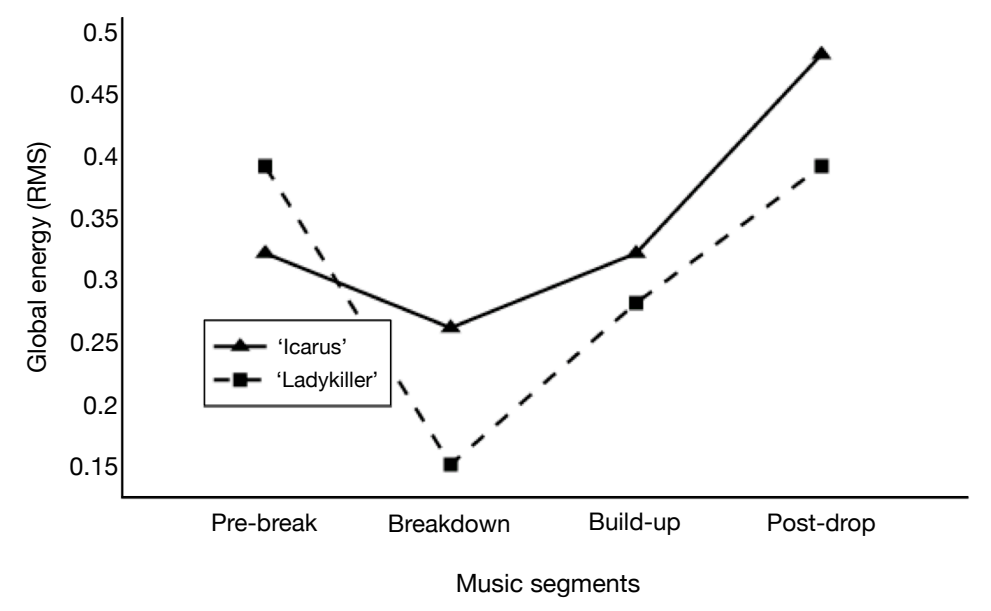

Figure 7. Top: Mean values of the audio amplitude for the pre-break, breakdown, build-up and post-drop segments. Bottom: Mean values of the global energy (RMS) for the pre-break, breakdown, build-up and post-drop segments. 


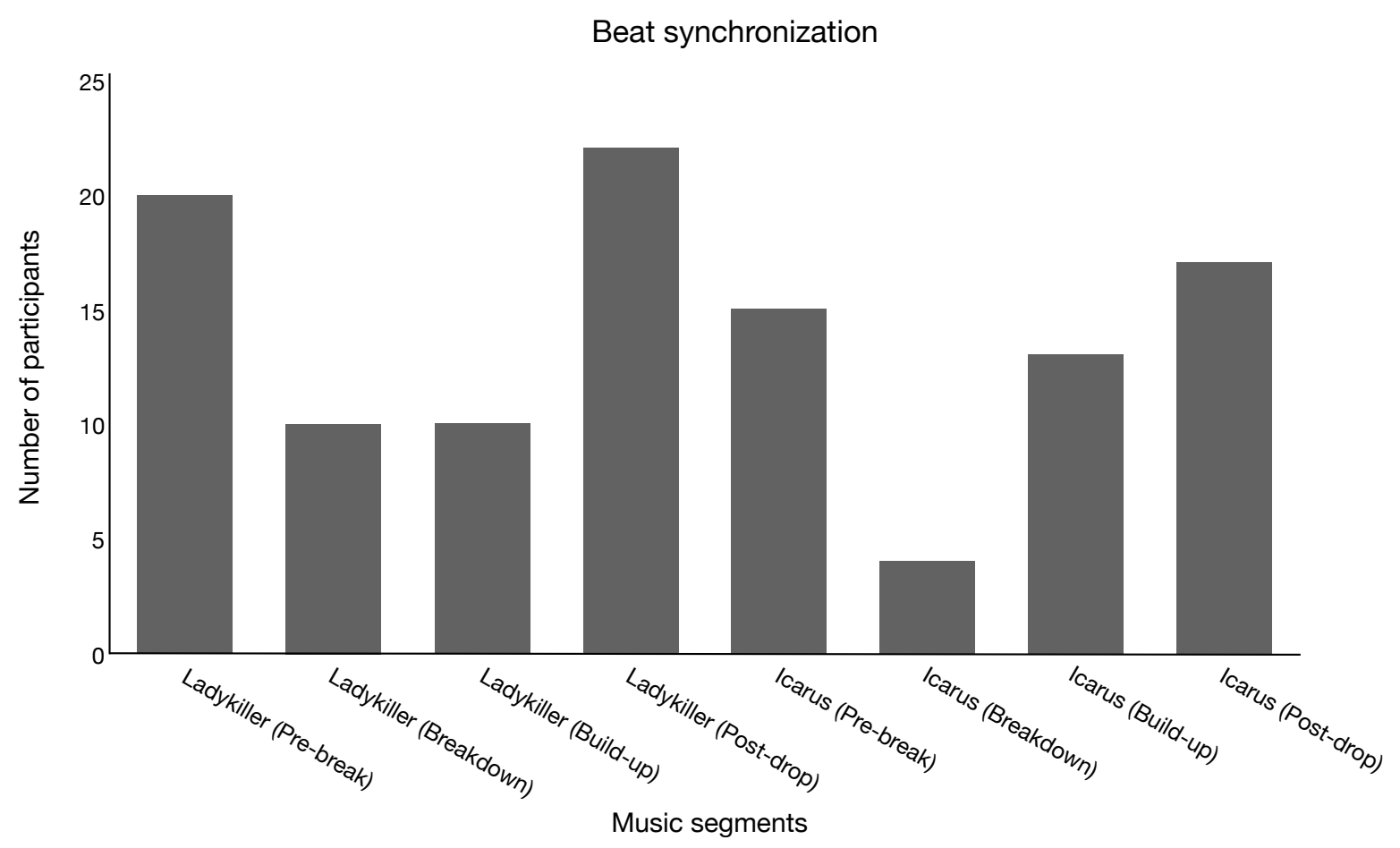

Figure 8 . Number of participants that vertically synchronize to the musical beat at quarter note level per music segment. 


\section{Vertical position - Ladykiller}
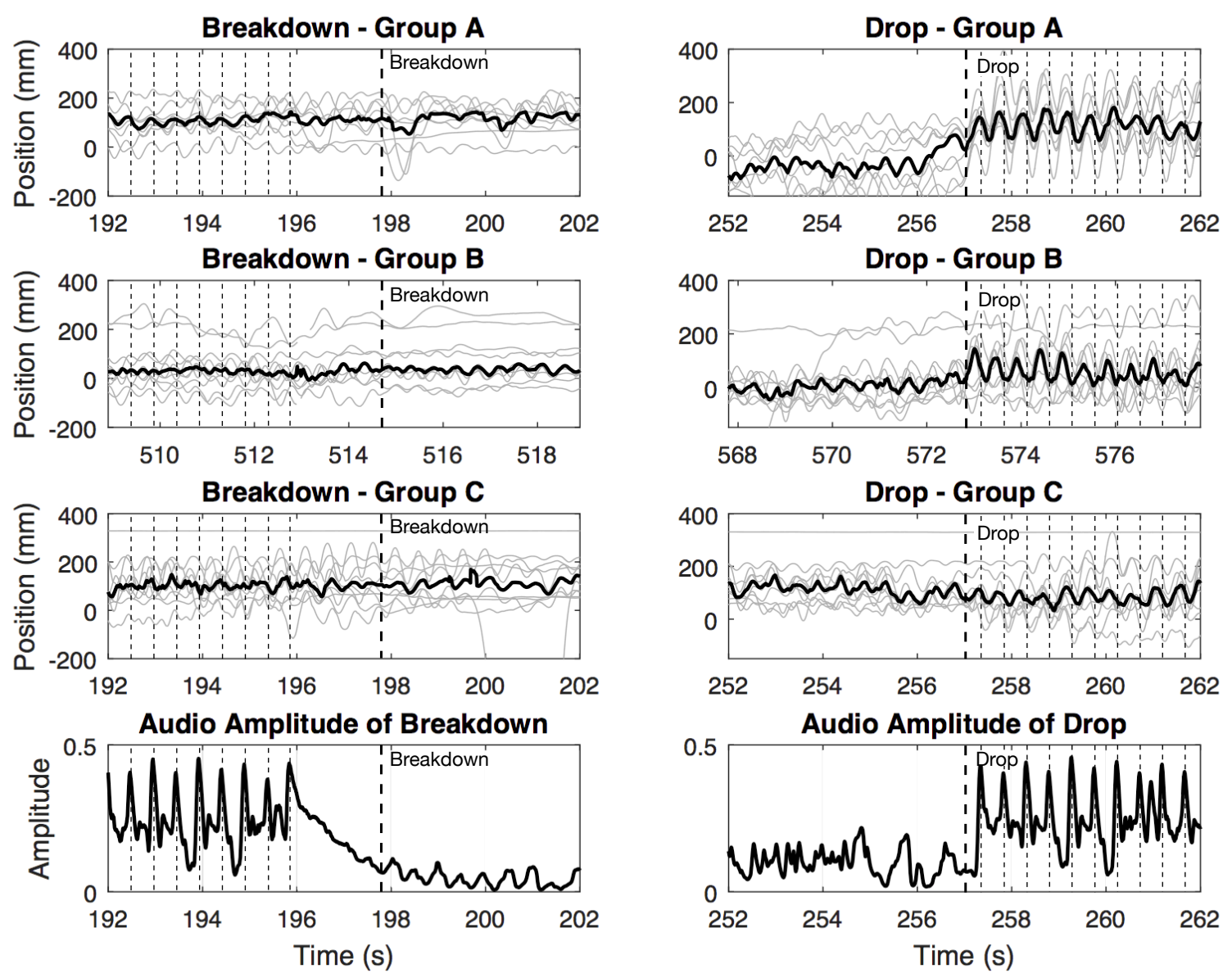

Figure 9. The vertical displacement for all subjects in Groups A, B and C in addition to the average of all the individual curves in black. The plots show 10-second segments of the transition between breakdown and drop of Ladykiller. The musical beat (quarter note level) is indicated with vertical dotted lines. The amplitude of audio is presented below the vertical position plots, for reference. 


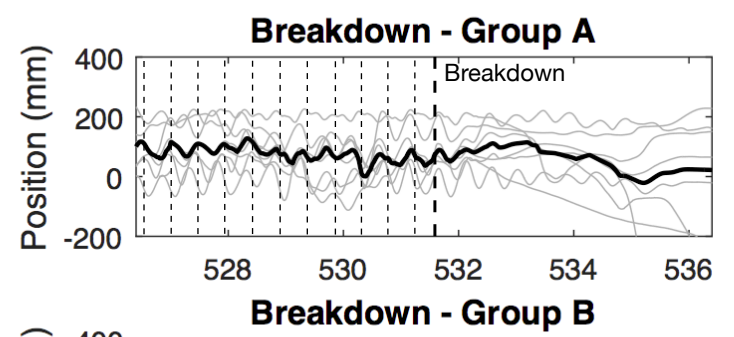

\section{Vertical position - Icarus}
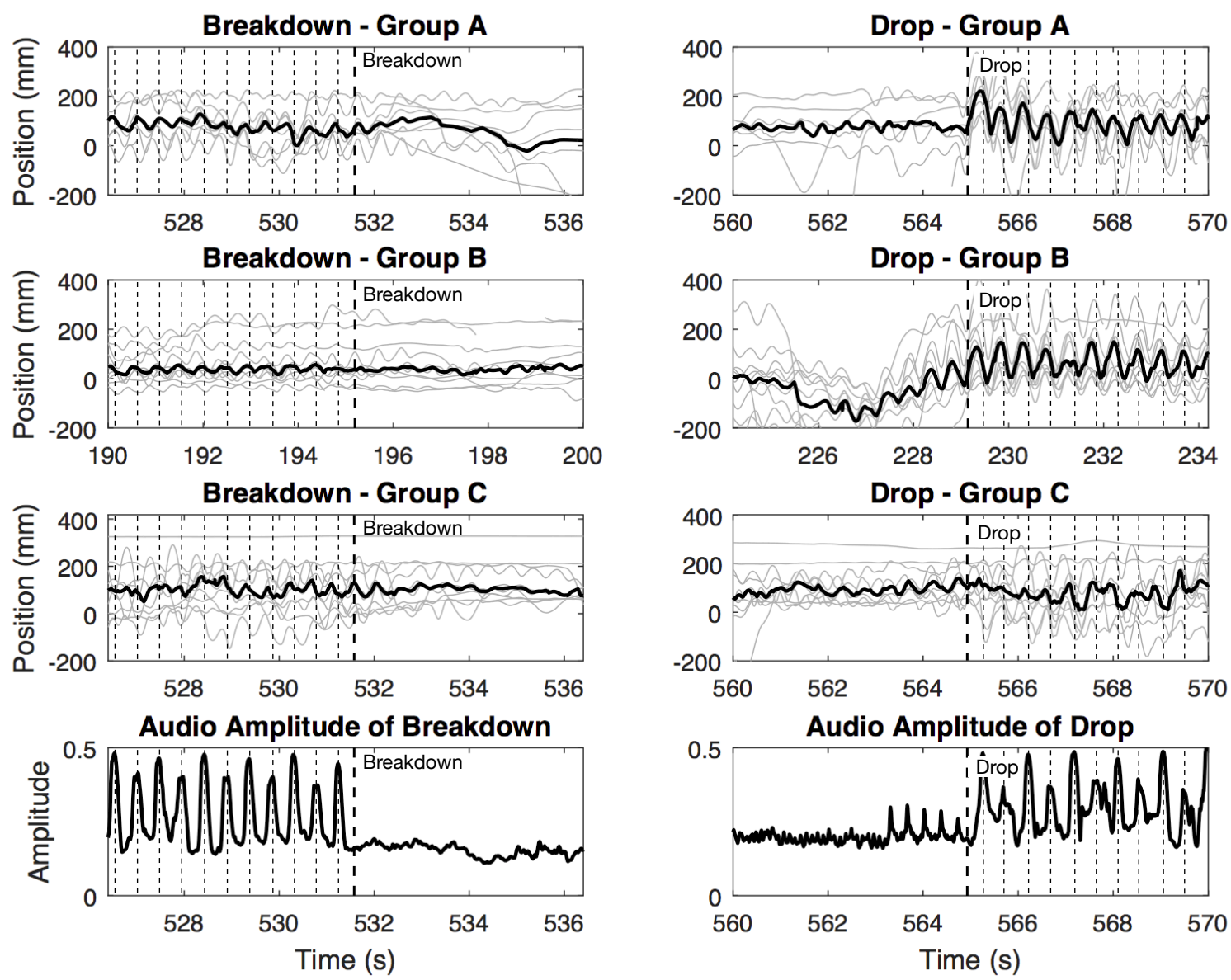

Figure 10. The vertical displacement for all subjects in Groups A, B and C in addition to the average of all the individual curves in black. The plots show 10-second segments of the transition between breakdown and drop of Icarus. The musical beat (quarter note level) is indicated with vertical dotted lines. The amplitude of audio is presented below the vertical position plots, for reference. 